\title{
Study of immunogenic properties of transmissible gastroenteritis virus antigen conjugated to gold nanoparticles
}

\author{
Pavel V. Mezhenny ${ }^{1 *}$, Sergej A. Staroverov ${ }^{2,3}$, Aleksandr S. Fomin ${ }^{2,3}$, Aleksej A. Volkov ${ }^{1}$, \\ Ivan Y. Domnitsky ${ }^{1}$, Sergej V. Kozlov ${ }^{1}$, Vladislav N. Laskavy ${ }^{3}$, and Lev A. Dykman ${ }^{2}$ \\ ${ }^{1}$ Saratov State Agrarian University, 1 Teatralnaya Square st., Saratov 410012, Russia \\ 2 IBPPM RAS, 13 Prospekt Entuziastov, Saratov 410049, Russia \\ ${ }^{3}$ Saratov Scientific and Research Veterinary Institute, 6, 53 ${ }^{\text {rd }}$ Strelkovaya diviziya st., Saratov 410028, Russia \\ * e-mail: v1rus-m@rambler.ru
}

\begin{abstract}
There was performed the study of immunogenic properties of the transmissible gastroenteritis virus antigen conjugated to gold nanoparticles. In comparative immunobiological studies there was found that immunization of guinea pigs driven by the colloidal gold conjugated to transmissible gastroenteritis virus antigen of swine, leads to activation of the respiratory activity of lymphoid cells and peritoneal macrophages, which is directly related to increased activity of antibodyproducing cells and activation of antibody generating. The obtained data suggest that the colloid particles promote antigen presentation to the reticuloendothelial system organs. In addition, there was established that these carriers stimulate production of proinflammatory cytokines, which leads to a complete and consistent immune response of both cellular and humoral components of immune system. (C) 2016 Journal of Biomedical Photonics \& Engineering.
\end{abstract}

Keywords: Gold Nanoparticles, nanomaterials, transmissible gastroenteritis virus, cytokines.

Paper \#3121 received 2016.12.02; accepted for publication 2016.12.29; published online 2016.12.31. doi: 10.18287/JBPE16.02.040308. [Saratov Fall Meeting 2016 Special Issue].

\section{References}

1. Q. H. Cheng, and X. Y. Niu, "Investigation on the porcine epidemic diarrhea prevalent on Qinhai," Vet. Sci. 22, 22-23 (1992).

2. B. E. Straw, S. D'Allaire, W. L. Mengeling, and D. J. Taylor (eds.) Disease of Swine, Iowa State University Press, Ames (2000).

3. B. Delmas, J. Gelfi, and H. Laude, "Antigenic structure of transmissible gastroenteritis virus. II. Domains in the peplomer glycoprotein," J. Gen. Virol. 67(7), 1405-1418 (1986).

4. L. S. Sturman, C. S. Riehard, and K. V. Holmes, "Proteolytic cleavage of the E2 glycoprotein of murine coronavirus by trypsin and separation of two different $90 \mathrm{~K}$ cleavage fragments," J. Gen. Virol. 56(3), 904-911 (1985).

5. R. A. Moxley, and L. D. Olson, "Clinical evaluation of transmissible gastroenteritis virus vaccines and vaccination procedures for inducing lactogenic immunity in sows," Am. J. Vet. Res. 50(1), 111-118 (1989).

6. R. Mout, D. F. Moyano, S. Rana, and V. M. Rotello, "Surface functionalization of nanoparticles for nanomedicine," Chem. Soc. Rev. 41(7), 2539-2544 (2012).

7. R. Bhattacharya, and P. Mukherjee, "Biological properties of "naked" metal nanoparticles," Adv. Drug Del. Rev. 60(11), 1289-1306 (2008).

8. E. C. Dreaden, A. M. Alkilany, X. Huang, C. J. Murphy, and M. A. El-Sayed, "The golden age: gold nanoparticles for biomedicine," Chem. Soc. Rev 41(7), 2740-2779 (2012).

9. L. A. Dykman, and N. G. Khlebtsov, "Gold nanoparticles in biomedical applications: recent advances and perspectives," Chem. Soc. Rev. 41(6), 2256-2282 (2012). 
10. L. A. Dykman, S. A. Staroverov, V. A. Bogatyrev, and S. Yu. Shchyogolev (eds.), Gold nanoparticles as an antigen carrier and an adjuvant, Nova Science Publishers, New York (2010).

11. S. A. Staroverov, I. V. Vidyasheva, K. P. Gabalov, O. A. Vasilenko, V. N. Laskavyi, and L. A. Dykman, "Immunostimulatory effect of gold nanoparticles conjugated with transmissible gastroenteritis virus," Bull. Exp. Biol. Med. 151(4), 436-439 (2011).

12. S. A. Staroverov, A. A. Volkov, S. V. Larionov, P. V. Mezhennyy, S. V. Kozlov, A. S. Fomin, and L. A. Dykman, "Study of transmissible gastroenteritis virus antigen-conjugated immunogenic properties of selenium nanoparticles and gold," Life Science J. 11(11), 456-460 (2014).

13. G. Frens, "Controlled nucleation for the regulation of the particle size in monodisperse gold suspensions," Nature Phys. Sci. 241(105), 20-22 (1973).

14. N. G. Khlebtsov, and L. A. Dykman, "Optical properties and biomedical applications of plasmonic nanoparticles,” J. Quant. Spectrosc. Radiat. Transfer. 111(1), 1-35 (2010).

\section{Introduction}

For the past few years, there has been a rapid development in designing nanovaccines which are to solve relevant problems of prevention and treatment of human and animal diseases. The use of nanovaccines implies the delivery of protective antigens to immune cells with the help of nanoscale carriers. Nanoparticles produced according to the methods of chemical and biological synthesis are used in designing nanovaccines. Metal nanoparticles seem of great interest. Affecting the immune system, they mimic the properties of natural pathogens eliciting a maximum immune response and do not have side effects.

Transmissible gastroenteritis of pigs (TGE) is a highly contagious acute disease in pigs of all age groups with such symptoms as vomiting, excessive diarrhea, dehydration. It has high mortality rate, especially among piglets in their first 10 days of life. The disease greatly harms hog-raising farms $[1,2]$.

TGE pathogen is a RNA virus belonging to the family Coronaviride, genus Alphacoronavirus, species 1a. The virion is circular in shape with a diameter ranging from 75 to $160 \mathrm{~nm}$. The nucleocapsid is a flexible spiral that contains a single strained RNA and a great number of nucleocapsid protein molecules [3, 4]. The virus replication takes place in the cytoplasm of mature epithelial cells located on the tips of villi in the small intestine.

Vaccination is the essential protection of animals against TGE. A veterinary drug market provides a high number of commercial vaccines preventing TGE. However, traditional inactivated vaccines have a range of disadvantages: they contain $99 \%$ of ballast substances which make the vaccine reactogenic; vaccines contain toxic agents used to inactivate microbial cells (phenol, formaldehyde). Also, inactivated vaccines are known to be less immunogenic because empty viral particles are unable to initiate cellular immunity. Therefore, vaccination against TGE is still considered to be a significant problem in veterinary [5].

Nowadays, there is a great number of research works dedicated to the study and use of various nanometer structures as universal carriers of biologically active substances to target cells $[6,7]$. To reach the target cell in vivo, a nanoparticle has to overcome a lot of obstacles which are natural barriers against nonshared antigens in the animal body [8]. Gold nanoparticles as antigens and therapeutic agent carries, as well as structures synthesized on their base, are widely used in contemporary medicine and biology in immunological and therapeutic ways [9]. The ability of gold nanoparticles to provoke a humoral immune response to weak immunogenic antigens and haptens seem of great interest [10]. There are some data on immune stimulating ability of gold nanoparticles conjugated with a TGE virus $[11,12]$.

This research is aimed at the study of immunogenic qualities of colloidal gold (CG) nanoparticles conjugated to TGE virus antigens.

\section{Materials and Research Methods}

The research used the capsid protein of a TGE virus as an antigen. The protein was obtained in a virological laboratory of the Saratov veterinary research institute of Russian Academy of Sciences.

Gold nanoparticles of a circular shape with an average diameter of $15 \mathrm{~nm}$ were obtained according to Frens [13] method, with the use of balancing redox reaction of chloroauric acid (Sigma-Aldrich, USA) and sodium citrate (Fluka, Switzerland). The balancing was conducted when $242.5 \mathrm{ml}$ of $0.01 \%$ of water solution of chloroauric acid were heated in an Erlenmeyer flask on a magnetic stirrer with a reverse water refrigerator up to $100^{\circ} \mathrm{C}$. Then, $7.5 \mathrm{ml}$ of $1 \%$ sodium citrate solution were added.

The diameter of the synthesized AuNPs was measured with the help of UV-Vis spectrometer Specord S 250 (AnalytikJena, Germany), the transmission electron microscope Libra 120 (CarlZeiss, Germany) and the particle size and Zeta potential analyzer ZetasizerNano-ZS (Malvern, UK); see the reference [14].

There were formed 3 groups of animals (guinea pigs), 9 heads in each, in order to do an immunobiological research based on analogue principle. The animals were immunized subcutaneously (along the spine) twice with an interval of 10 days.

The first group of guinea pigs were injected a solution of TGE virus antigen in a dosage of $1 \mathrm{ml}$. The second group was injected a conjugated antigen of TGE 
and $\mathrm{CG}$ in a dosage of $1 \mathrm{ml}$. The third group was injected a physiological solution in a dosage of $1 \mathrm{ml}$.

Euthanasia of guinea pigs was carried out 10 days after the last shot. Then, the serum was taken for the immunological research.

The concentration of interleukins in the serum was measured with the help of the reagent kit for the enzyme immunoassay detection of IL-1 $\beta$, IL-6 and INF- $\gamma$ (Vector-Best, Russia) on an immunoassay analyzer Plate Screen (Hospitex Diagnostics, Italy).

The titer of the obtained antibodies in the blood serum was measured with the help of enzyme-linked immunosorbent assay (ELISA) with the use of antibodies marked with horseradish peroxidase to IgG of guinea pigs (Jackson ImmunoResearch, UK); synthetic peptide was used as a fixed antigen. The reaction results were registered on a microplate spectrometer Plate Screen (Hospitex Diagnostics, Italy). Shortly, the antigen dissolved in a $0.01 \mathrm{M}$ PBS in the ratio 1:100 was adsorbed, and then it was incubated during the night at $+4^{\circ} \mathrm{C}$. The unbound sites in the hole were blocked with $200 \mu 1$ of $2 \%$ dried milk in a $0.01 \mathrm{M}$ PBS for 1 hour in a shaker. $100 \mu \mathrm{l}$ of animal serum dissolved in PBS 1:10 were brought in and then dissolved twice in PBS and incubated for 1 hour on a thermoshaker at $37^{\circ} \mathrm{C}$; later it was washed with $200 \mu \mathrm{l}$ of PBS three times with 10 minute intervals in a shaker. $100 \mu \mathrm{l}$ of antigens marked with horseradish peroxidase (Jackson ImmunoResearch, UK) and dissolved in BS 1:500 were inserted into the holes and incubated for 1 hour on a thermoshaker at $37^{\circ} \mathrm{C}$. Then, a triple washing was carried out with $200 \mu \mathrm{l}$ of PBS with 10 minute intervals in a shaker. The antigen-antibody reaction was performed with the help of $100 \mu \mathrm{l}$ of $0.006 \%$ o-Phenylenediamine (OPDA) in $0.1 \mathrm{M}$ citrate buffer adding $0.01 \%$ hydrogen superoxide. The reaction was stopped with $100 \mu \mathrm{l}$ of $0.1 \mathrm{M}$ sulfuric acid.

Accommodation and care of animals as well as their euthanasia were conducted according to the guidelines of the Ministry of Healthcare of the Russian Federation for experimental biological clinics and in accordance with "European Convention for the protection of vertebrate animals used for experimental and other scientific purposes".

The obtained results were statistically processed by the standard procedures integrated in Excel 2007 software (Microsoft Corp., USA). After the arithmetic mean and the standard deviation for a given data sample had been found, we determined the standard error of the arithmetic mean and its confidence limits with account of Student's $t$ coefficient ( $n, p)$ [number of measurements $n=3$, significance level $=95 \%(p=0.05)$ ]. These results are presented as histograms. The significance of differences between individual samples was evaluated by a two-sample unpaired Student's t test with unequal variances. Differences were considered significant when the experimentally found pexp value was $\leq 0.05$. The reliability of the changes recorded in the results of each of the experiments described above for the entire set of antigen formulations examined was assessed by one-way analysis of variance (ANOVA) by using Fisher's ratio test. The dependences found were considered significant at $\mathrm{F}>\mathrm{F}_{\text {crit }}$, where the critical value $F_{\text {crit }}$ at $n=3$ and $m=4-5$ (number of data sets) corresponded to $\mathrm{p}=0.05$ (with the number of degrees of freedom (df) lying between 4 and 14) and the effective value peff was $<0.05$.

\section{Results and Discussion}

The diameter of the synthesized gold nanoparticles was measured by the methods of spectrophotometry, transmission electron microscopy (TEM) and dynamic light scattering (DLS) (see figure 1). The absorption spectrum maximum of the obtained sol was $\lambda_{\text {max }}=529.1 \mathrm{~nm}$ at the optical density of $A_{520}=1.2$. According to TEM and DLS data, the average diameter of the obtained nanoparticles was $15.7 \mathrm{~nm}$.

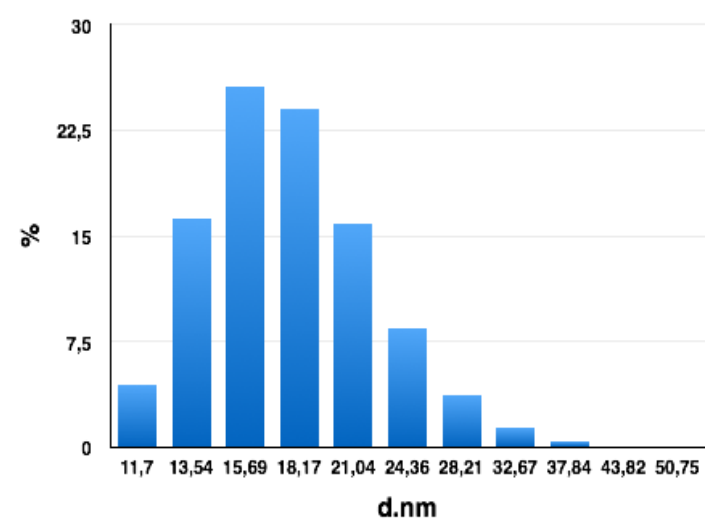

(a)

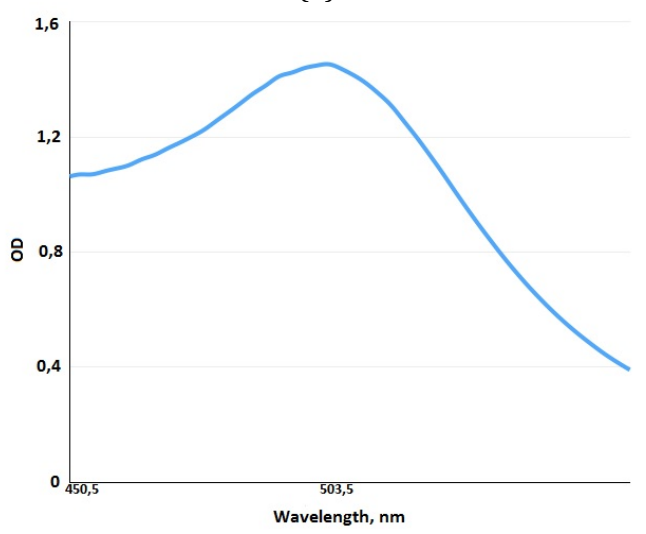

(b)

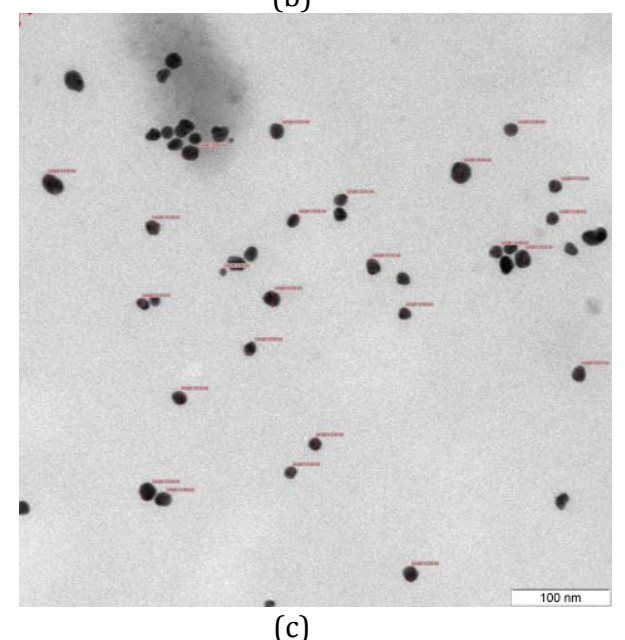

Fig. 1 The distribution of particle sizes (a), absorption spectrum (b) and TEM image (c). 
Table 1 Cytokine concentration in the blood serum of the guinea pigs immunized with different drugs.

\begin{tabular}{|c|c|c|c|}
\hline \multirow{2}{*}{ Group } & \multicolumn{2}{|c|}{ Indices } \\
\cline { 2 - 4 } & IL-1 $\beta, \mathrm{pg} / \mathrm{ml}$ & IL-6, pg/ml & INF- $\gamma, \mathrm{pg} / \mathrm{ml}$ \\
\hline Solution of TGE virus antigen & $6.93 \pm 0.91$ & $6.68 \pm 0.46$ & $45.06 \pm 1.69$ \\
\hline TGE virus antigen and CG conjugate & $8.10 \pm 0.74$ & $8.59 \pm 1.01$ & $60.44 \pm 9.91$ \\
\hline Physiological solution & $4.93 \pm 0.71$ & $4.75 \pm 0.66$ & $34.10 \pm 6.65$ \\
\hline
\end{tabular}

Table 2 Antiviral Antibody Titre.

\begin{tabular}{|c|c|c|}
\hline & TGE virus antigen & Antigen and CG conjugate \\
\hline Antibody titres & $1: 8192$ & $1: 16384$ \\
\hline
\end{tabular}

The data show that the highest concentration of INF$\gamma$ is observed in animals immunized with the antigen conjugated to gold nanoparticles $(60.44 \pm 9.91 \mathrm{pg} / \mathrm{ml})$.

The study of interleukin-1 beta (IL-1 $\beta$ ) concentration in the plasma of the animals demonstrates (table 1 ) that the highest IL-1 $\beta$ concentration was also observed in the group immunized with the antigen conjugated to gold nanoparticles. It was $8.10 \pm 0.74$ $\mathrm{pg} / \mathrm{ml}$. The IL- $1 \beta$ concentration in the group immunized with the native antigen was $6.93 \pm 0.91 \mathrm{pg} / \mathrm{ml}$.

The highest level of IL-6 was observed in the group of animals immunized with the antigen conjugated to CG. It was $8.59 \pm 1.01 \mathrm{pg} / \mathrm{ml}$. The IL- 6 concentrations in the group immunized with the native antigen and in the control group were $6.68 \pm 0.46 \mathrm{pg} / \mathrm{ml}$ and $4.93 \pm 0.71$ $\mathrm{pg} / \mathrm{ml}$ respectively.

Analyzing the titres of the obtained antibodies, one can notice that the antibody titre of the animals immunized with the CG conjugate is $1: 16384$, which is twice higher than the antibody titer of the animals in the control group (see table 2).

Thus, based on the undertaken research, it seems possible to conclude that the vaccination of animals with the TGE virus antigen conjugated with $\mathrm{CG}$ activates antibody production. Besides that, this carrier stimulates interferon and cytokines production what provokes a full and balanced immune response of cellular as well as humoral immunity at prophylactic immunization. The collected data allow suggesting that colloidal particles functioning as nanocarries induce the increase of antigen expression on the surface of antigenpresenting cells and likewise they favor the effective presentation of viral peptides for cytotoxic $T$ lymphocytes and natural killer cells.

\section{Acknowledgments}

This study was supported by the Russian Science Foundation (grant no. 15-14-00002). 